\title{
Olfactory detection thresholds in man under conditions of rest and exercise'
}

HERBERT STONE, GORDON PRYOR AND JUDITH COLWELL STANFORD RESEARCH INSTITUTE

Detection thresholds for seven odorants were measured under conditions of rest and exercise. The test panel comprised six males with previous experience in odor detection. Exercise was maintained constant by using a modified bicycle positioned within the context of an air-dilution olfactometer. The effects of exercise were idiosyncratic for Ss: odor sensitivity was increased in some $S s$, decreased in some, and not changed in others. Results of these experiments are discussed in terms of intra-subject variance within sessions and from session to session. In addition, two test techniquesone a fixed series and the other a tracking procedure-were evaluated for rapid estimation of an odor threshold. The tracking procedure facilitated prompt detection of changes in sensitivity for individual Ss.

Recent reports have focused attention on the paucity of quantitative data on the olfactory sensitivity of man (Benjamin et al, 1964; Wenzel \& Sieck, 1966; Stone, 1966). Thus, attempts to utilize available psychophysical data in validating current theories of olfaction have not been successful. The present study, part of a general program on olfactory detection reactions in man, was undertaken in an effort to establish baseline data on human odor-sensitivity. The data reported herein are the odor-detection thresholds $\left(I_{t}\right)$ for man under conditions of rest and mild physical exercise.

\section{Subjects}

\section{METHOD}

The Ss were six males chosen from a larger group on the basis of their olfactory sensitivity to a standard stimulus, propionic acid. The criteria for selection of the test panel were (1) achievement of a tenfold range among $\mathrm{Ss}$ in sensitivity to this stimulus, (2) absence of obvious olfactory aberrations (nasal diseases, allergies), and (3) consistent performance in odor detection. Ss were instructed to not smoke or chew gum for at least $30 \mathrm{~min}$. before each session and to not use perfumed shaving lotions on test days. No attempt was made to control for eating except during the $1 / 2 \mathrm{hr}$, before testing.

\section{Apparatus}

The olfactometer is an air-dilution system based on equipment described elsewhere (Ough \& Stone, 1961; Stone \& Bosley, 1965). Air, supplied in excess of $20 \mathrm{CFM}$ by a high-speed blower, is passed over a refrigeration coil. A portion of this cooled air is picked up by a small, high-speed blower and then passed over a rheostat-controlled heating coil and through an absolute filter and an activated-carbon
}

filter bed into a glass tubing system. This "odor-free," temperature-controlled air flows continuously through a series of regulating valves and a flowmeter (FisherPorter, 14.6 CFM capacity) and, uitimately, into a Plexiglas hood. The S's head is enclosed in the hood. Delivery of a stimulus to $S$ is accomplished by metering high-purity, water-pumped $\mathrm{N}_{2}$ through one of a series of four precision flowmeters into a diffusion bulb. The gas is saturated by passing it through a sintered-glass sparger immersed in the stimulus. This saturated vapor is returned to the main air stream, mixed, and carried to the hood.

Temperature of the stimulus was maintained at $25^{\circ} \pm 0.25^{\circ} \mathrm{C}$ by means of a thermistor-regulated water bath. For compounds with a high vapor pressure, the diffusion bulb was immersed in a constant-temperature $\left( \pm 3.0^{\circ} \mathrm{C}\right)$ cooling bath.

Communication between $\mathrm{E}$ and $\mathrm{S}$ during testing was through a light panel positioned in front of $S$; a partition prevented $S$ from seeing $E$. A light signalled $S$ that a trial had begun, and $S$ indicated whether he thought a stimulus was present or absent by pressing the appropriate button in front of him. After $S$ responded, another light signalled $S$ whether an odor was actually present on that trial. In all test series each stimulus was presented for $10 \mathrm{sec}$, with a 15 -sec. interval between presentations.

Concentrations of the odorants delivered to $\mathrm{S}$ were calculated from the vapor pressure, the experimental temperature, and the flow rates of the gas, in accordance with previously established procedures (Stone et al, 1962).

An exercise machine (modified bicycle, T.J. Thomas Co., Inc., N. Y.), with a speedometer attached, was mounted in the experimental room so that $S$ could maintain a constant rate of pedaling while sitting with his head in the Plexiglas hood during the exercise phase of testing.

\section{Test Odorants}

Odorants tested were: n-heptanol, n-octanol, cyclohexanone, methyl isobutyl ketone, menthone, phenylisothiocyanate, and allyl-isothiocyanate. Purity of stimuli was assured by redistillation; only the constant boiling fraction was used. Purity, checked by gasliquid chromatography, was always $>99 \%$.

\section{Test Condifions}

Ss were tested under two conditions. In the firstrest (R) -S sat quietly; in the second-physical exercise $(\mathrm{PE})$ - he was required to pedal at $20 \mathrm{mph}$ in the free- 
Table 1. I Values for Five Odorants Under Conditions of Rest and Exercise

\begin{tabular}{|c|c|c|c|c|c|c|c|c|c|c|}
\hline \multirow[b]{2}{*}{$S$} & \multicolumn{2}{|c|}{$\begin{array}{l}\text { Heptanol } \\
\left(\mathrm{mg} / 1 \times 10^{-5}\right)\end{array}$} & \multicolumn{2}{|c|}{$\begin{array}{c}\text { Octanol } \\
\left(\mathrm{mg} / 1 \times 10^{-5}\right)\end{array}$} & \multicolumn{2}{|c|}{$\begin{array}{l}\text { Stimulus } \\
\text { Cyciohexanone } \\
\left(\mathrm{mg} / 1 \times 10^{-4}\right)\end{array}$} & \multicolumn{2}{|c|}{$\begin{array}{c}\text { Methyl I sobutyl } \\
\text { Ketone } \\
\left(\mathrm{mg} / 1 \times 10^{-4}\right)\end{array}$} & \multicolumn{2}{|c|}{$\begin{array}{c}\text { Methone } \\
\left(\mathrm{mg} / 1 \times 10^{-3}\right)\end{array}$} \\
\hline & $R$ & PE & $\mathrm{R}$ & $P E$ & $R$ & $P E$ & $R$ & PE & $R$ & $P E$ \\
\hline$R G$ & 3.44 & 5.18 & 5.16 & 6.83 & 6.30 & 8.33 & 12.19 & 9.95 & 15.81 & 14.19 \\
\hline GP & 11.39 & 10.41 & 7.35 & 7.03 & 20.07 & 15.67 & 20.67 & 11.95 & 52.31 & 29.70 \\
\hline VP & 14.98 & 14.04 & 3.28 & 3.82 & 29.56 & 25.29 & 9.82 & 11.14 & 111.01 & 106.40 \\
\hline WJ & 16.33 & 25.14 & 4.25 & 20.96 & 7.14 & 11.75 & 3.28 & 17.92 & 26.85 & 96.00 \\
\hline HT & 3.25 & 3.03 & 6.06 & 5.40 & 11.37 & 12.56 & 9.10 & 7.82 & 28.42 & 27.10 \\
\hline DS & 2.30 & 2.25 & 2.65 & 2.45 & 12.54 & 13.65 & 3.36 & 12.96 & 23.07 & 13.79 \\
\hline $\bar{x}$ & 5.09 & 5.21 & 4.90 & 5.42 & 11.48 & 12.39 & 9.73 & 11.95 & 42.88 & 47.86 \\
\hline SD & 4.13 & 3.68 & 1.94 & 2.11 & 6.05 & 2.80 & 6.45 & 3.32 & 40.52 & 41.94 \\
\hline
\end{tabular}

wheeling mode for $1 \mathrm{~min}$. before testing began and throughout the testing period. Under either condition, $S$ indicated whether or not he detected an odor when $E$ turned on the light that signalled for a response. All tests were carried out between $8: 30$ and 12:00 AM. Ss were tested twice each week, for an hour each time.

\section{Test Procedures}

For the first five odorants, a forced-choice, randomized, single-sample method of presentation (Procedure A) was used (Guilford, 1954). S was presented with the highest of a series of selected test concentrations as an orientation stimulus (series established by Es). A descending series was then presented until a stimulus concentration was reached which $\mathrm{S}$ could no longer positively identify. This stimulus, the one just above it, and the next three in order below were taken as the test concentrations. (The concentration series was usually $\log _{2}$; however, it was often necessary to further reduce these differences.) These five concentrations and three blanks, each introduced randomly, constituted a replication; there were four replications in a test series. Each test series required $12 \mathrm{~min}$. to complete and was followed by a 2-min. rest. After two test series, $S$ was allowed a 5-min. rest period out of the apparatus. Each $S$ was tested in six test series-four under the rest condition and two under the exercise condition. Four series were completed in a 1-hr. test session.
Data for each $S$ under each test condition were subjected to probit analysis (Finney, 1962) to determine the detection threshold $\left(\mathrm{I}_{t}\right)$, its variance, and the parameters of the probit equation of the line. Estimates of $I_{t}$ for each $S$ under each condition were then subjected to analysis of variance to determine intersubject variability and the variability associated with test conditions.

Procedure B (also forced-choice, randomized, singlesample) differed from Procedure $A$ in that the test series was not fixed and each $S$ was tested during four 1-hr. sessions. For each test series, E used a "tracking" procedure in which $\mathrm{S}$ was presented with many stimuli close to his detection threshold for that series. First, a descending series was presented until $S$ could no longer detect the stimulus. This was facilitated by his rating the intensity by means of another signal system. At this point he was presented with random test concentrations (and blanks) in the immediate vicinity of those at which the response was lost. The range of concentrations presented was successively narrowed until an approximation of the threshold was achieved. Sufficient observations, interspersed with blank trials, were taken until 50\% \pm correct responses occurred. The series was then terminated, after which $\mathbf{E}$ assigned a best estimate of $I_{t}$ for that series. The entire procedure took approximately $12 \mathrm{~min}$. Each odorant was tested for 16 series, equally divided between rest and exercise. In a $1 \mathrm{hr}$.

Table 2. It Values for Phenyl-Isothiocyanate Under Conditions of Rest and Exercise ${ }^{a}$

\begin{tabular}{|c|c|c|c|c|c|c|c|c|c|c|c|c|}
\hline \multirow[b]{3}{*}{$S$} & \multicolumn{8}{|c|}{ Doy } & \multicolumn{2}{|c|}{$R$} & \multicolumn{2}{|c|}{$P E$} \\
\hline & \multicolumn{2}{|c|}{1} & \multicolumn{2}{|c|}{2} & \multicolumn{2}{|c|}{3} & \multicolumn{2}{|c|}{4} & \multirow[t]{2}{*}{$\bar{x}$} & \multirow[t]{2}{*}{ SD } & \multirow[t]{2}{*}{$\overline{\bar{x}}$} & \multirow[t]{2}{*}{ SD } \\
\hline & $R$ & $P E$ & $R$ & $P E$ & $\mathrm{R}$ & PE & $R$ & PE & & & & \\
\hline GP & 3.96 & 3.67 & 4.64 & 6.55 & 12.35 & 14.79 & 19.90 & 10.95 & 10.21 & 7.04 & 8.99 & 5.23 \\
\hline VP & 2.82 & 2.96 & 2.00 & 2.00 & 1.33 & 1.24 & 3.19 & 2.70 & 2.33 & 0.98 & 2.22 & 0.90 \\
\hline WJ & 0.24 & 2.54 & 0.53 & 4.10 & 0.27 & 1.73 & 0.24 & 0.38 & 0.32 & 0.13 & 2.19 & 1.46 \\
\hline HT & 0.38 & 0.93 & 3.75 & 3.26 & 1.97 & 1.32 & 0.80 & 1.10 & 1.44 & 1.24 & 1.65 & 1.27 \\
\hline DS & 4.38 & 0.24 & 3.69 & 1.33 & 5.69 & 2.00 & 4.10 & 1.88 & 2.23 & 1.25 & 1.36 & 1.04 \\
\hline $\bar{x}$ & 2.36 & 2.07 & 2.92 & 3.45 & 4.32 & 4.22 & 5.65 & $3.40^{\circ}$ & 3.30 & 3.49 & 3.28 & 9.08 \\
\hline SD & 1.84 & 1.38 & 1.76 & 2.04 & 4.71 & 6.06 & 7.67 & 4.11 & 4.70 & & 2.82 & \\
\hline
\end{tabular}

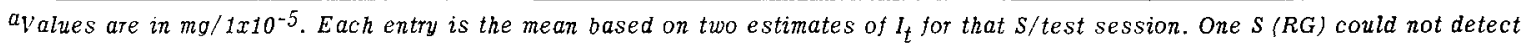
the stimulus. See text for additional discussion. 
session, there were four estimates of $I_{t}$ per $S$ and a total of eight estimates for each condition for each $\mathrm{S}$. This enabled us to obtain an estimate of the intrasubject variability under these test conditions.

For data from Procedure $B$, the mean $I_{t}$ under each condition was computed for all test series and was used as the best estimate for each S. An estimate of intrasubject variability was determined from the standard deviation around the mean $\mathrm{I}_{t}$ over test series. Intersubject variability and that resulting from the test conditions were determined by analysis of variance.

\section{RESULTS}

The $I_{t}$ values for each $S$ obtained with Procedure $A$ are shown in Table 1 as a function of rest and exercise. As expected, there were significant differences among odorants $(p<.001)$. Differences due to test conditions were not significant $(p>.05)$ nor did the interaction between odorants and test conditions reach an acceptable level of significance $(.10>p>.05)$. However, inspection of the table shows that exercise consistently increased sensitivity for some Ss, and decreased sensitivity for others, while some Ss were unaffected. The procedure used for these odorants did not allow a statistical evaluation of intrasubject changes.

The results for phenyl- and allyl-isothiocyanate are shown in Tables 2 and 3 , respectively. Analysis of variance showed that the main effect, restvs. exercise, was not significant for either odorant $(p>.05)$. For phenyl-isothiocyanate, the interaction between test conditions and days was significant $(p<.025)$, the interaction between test conditions and $S s$ was marginally signigicant $(p<.10)$, and the triple interaction (test conditions by days by $S s)$ was highly significant $(p<.001)$. For allyl-isothiocyanate, both double interaction terms and the triple interaction were highly significant $(p<.001) .^{2}$

The sequence of rest and exercise was counterbalanced in this experiment. Table 4 shows the $I_{t}$ values for each $\mathrm{S}$ according to test sequence for each of the four test sessions for allyl-isothiocyanate. No consistent pattern is apparent that would suggest
Table 4. Individual $\mathbf{t}_{\mathbf{t}}$ Values for Allyl-Isothiocyanate According to Test Sequence of Rest and Exercise ${ }^{q}$

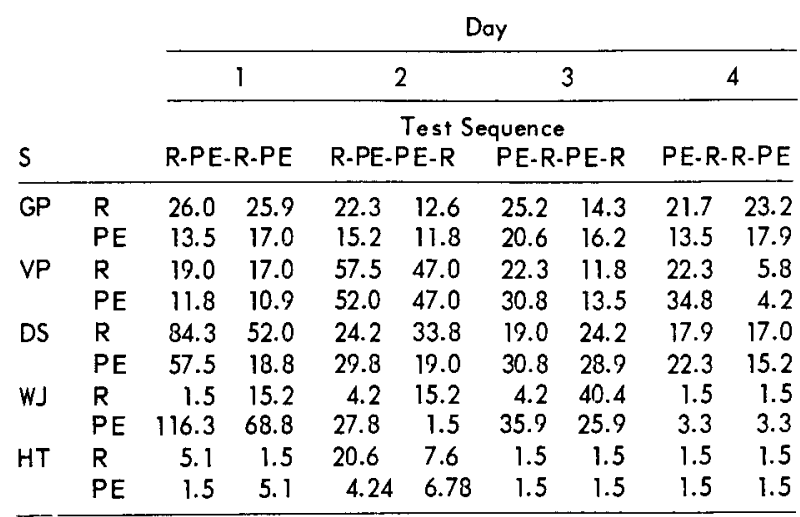

$a_{V}$ alues are in $\mathrm{mg} / 1 \times 10^{-5}$.

any carryover effects of the test conditions. However, the data show that there was some variability of the threshold even within a test session-considerable for some Ss (DS, WJ), but quite small for others (GP, $H T$ ). An interesting finding was that one $S$ (RG) was almost totally anosmic to both phenyl- and allylisothiocyanate; he was barely able to detect the $100 \%$ solution of either compound, though his sensitivity was normal for the five other odorants tested.

\section{DISCUSSION}

The combined $I_{t}$ values of four compounds used in this experiment, shown in Table 5, are in agreement with previously reported data (Laffort, 1963; Stone, 1963). This is especially significant in view of the different testing techniques utilized by the present investigators and others.

The specific conditions under which exercise affects $I_{t}$ are obscure at this time. It may be that the amount of exercise is critical; i.e., a given level may raise or reduce $\mathrm{I}_{\mathrm{t}}$ for a given $\mathrm{S}$. Under moderate forms of physical exercise there is an increase in blood circulation, swelling of the nares, and an increase in moisture vapor in the exhaled breath. According to Schneider and

Table 3. $I_{t}$ Values for Allyl-Isothiocyanate Under Conditions of Rest and Exercise ${ }^{a}$

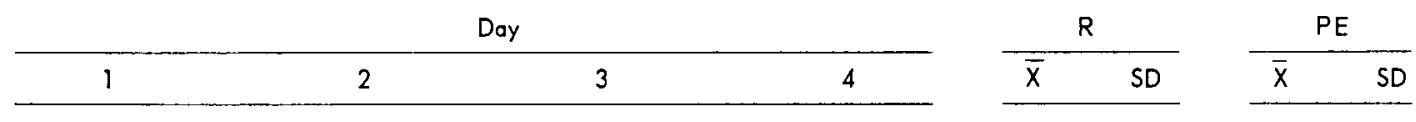

\begin{tabular}{|c|c|c|c|c|c|c|c|c|c|c|c|c|}
\hline$S$ & $\mathrm{R}$ & $\mathrm{PE}$ & $\mathrm{R}$ & PE & $\mathrm{R}$ & PE & $\mathrm{R}$ & PE & & & & \\
\hline GP & 25.8 & 15.2 & 17.5 & 13.5 & 19.7 & 18.4 & 22.4 & 15.7 & 21.4 & 5.1 & 15.7 & 3.5 \\
\hline VP & 18.0 & 11.3 & 52.2 & 49.5 & 17.1 & 22.1 & 14.1 & 19.5 & 25.3 & 17.8 & 25.6 & 18.2 \\
\hline WJ & 8.3 & 92.5 & 9.7 & 14.6 & 22.3 & 30.9 & 1.5 & 3.3 & 10.4 & 13.1 & 35.3 & 40.2 \\
\hline HT & 3.3 & 3.2 & 14.1 & 5.5 & 1.5 & 1.5 & 1.5 & 1.5 & 5.1 & 6.3 & 2.9 & 1.7 \\
\hline DS & 68.1 & 38.1 & 29.0 & 24.4 & 21.6 & 29.8 & 17.4 & 18.7 & 34.0 & 23.2 & 27.7 & 13.8 \\
\hline $\begin{array}{l}\bar{X} \\
\text { SD }\end{array}$ & $\begin{array}{l}24.7 \\
25.6\end{array}$ & $\begin{array}{l}32.0 \\
37.1\end{array}$ & $\begin{array}{l}24.5 \\
17.3\end{array}$ & $\begin{array}{l}21.5 \\
17.5\end{array}$ & $\begin{array}{l}16.4 \\
12.1\end{array}$ & $\begin{array}{l}20.5 \\
12.4\end{array}$ & $\begin{array}{c}11.3 \\
9.69\end{array}$ & $\begin{array}{l}11.7 \\
11.0\end{array}$ & $\begin{array}{r}19.2 \\
6.5\end{array}$ & 11.5 & $\begin{array}{r}21.4 \\
8.3\end{array}$ & 12.4 \\
\hline
\end{tabular}

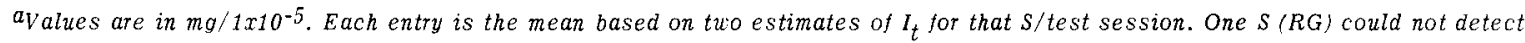
the stimulus. See text for additional discussion. 
Table 5. Comparison of $\mathbf{~}_{\mathrm{t}}$ Values with Reported Literature Data ${ }^{a}$

\begin{tabular}{lccc} 
Odorant $b$ & Present Study & Laffort (1963) & Stone (1963) \\
\hline n-Heptanol & $2.30-11.39$ & 27.3 & 111.7 \\
n-Octanol & $1.66-7.35$ & 1.13 & -- \\
Allyl-isothiocyanate & $5.1-34.0$ & 3.06 & -- \\
Phenyl-i sothiocyanate & $0.32-10.21$ & 4.08 & -- \\
\hline
\end{tabular}

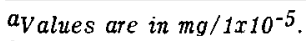

${ }^{b}{ }_{t}$ values for cyclohexanone, methyl-isobutyl-ketone, and methone have not been reported before.

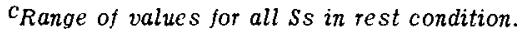

Wolf (1960), odor sensitivity was best in the presence of a "red, swollen, wet mucosa," provided the nares were not blocked. These authors suggested that contact of odorant with receptor sites was facilitated by the increased warmth and humidifying effects of nasal engorgement during hyperfunction. Thus, physical exercise could produce such an effect, which might be offset in some Ss by excess exercise. This might account for the variability in sensitivity (decrease and increase) noted in some Ss for some of the odorants in the present experiment.

No $S$ reported the exercise to be so exhausting that he missed the stimulus through inattention or that he experienced difficulty breathing through the nose. Since no olfactory examination was made of the Ss following the exercise, we can only speculate on the condition of the nares. Of course, it is also possible that the changes in the nose during physical activity are not similar to those changes noted by Schneider and Wolf in their Ss, all of whom were calm and not physically active. It is also possible that the increased sensitivity shown by some Ss was due to an increased mucus flow during exercise. Such an increased mucus flow might remove extraneous matter, including other odorants, from the olfactory region and thus facilitate perception of the incoming stimulus. In future experiments we plan to measure some of the physiological responses to exercise (e.g., changes in heart rate and respiration) and to establish the amount of work expended by the Ss.

Procedure B, "tracking," was more useful than Procedure A for rapid determination of thresholds. The latter technique, which utilized a fixed set of stimuli, did not allow adequate estimation of intrasession thresholds and thus precluded estimates of intrasubject variability within sessions or from day to day. The "tracking" procedure, however, enabled $\mathbf{E}$ to make optimum use of the information gained in a single test series.

The specific anosmia to the two isothiocyanates by RG was an unexpected finding. Since our panel was only six and all males, we have no idea what percentage of the population is anosmic to the isothiocyanates. Amoore (1966) has proposed that about $2 \%$ of the population has a specific anosmia. Data from people with specific anosmias may provide valuable information on primary odor sensations and families of odor types.

\section{References}

Amoore, J. E. Specific anosmias and primary odors. In N. Tanyolac (Ed.), Theories of odor and odor measurement. In press.

Benjamin, R. M., Halpem, B. P., Moulton, D. G., \& Mozell, M. M. The chemical senses. Ann. Rev. Psychol., 1965, 16, 381-416.

Finney, D. J. Probit analysis (2nd ed.). Cambridge, Mass.: University Press, 1962.

Guilford, J. P. Psychometric methods (2nd ed.). New York: McGrawHill, 1954.

Laffort, P. Essai de standardisation des seuils olfactifs humains pour 192 corps purs. Arch. Sci. Physiol., 1963, 17, 75-105.

Ough, C. S., \& Stone, H. An olfactometer for rapid and critical odor measurement. J. Food Sci., 1961, 26, 452-456.

Schneider, R. A., \& Wolf, S. Relation of olfactory acuity to nasal membrane function. J. appl. Physiol, 1960, 15, 914-920.

Stone, H. Determination of odor difference limens for three compounds. J. exp. Psychol., 1963, 66, 466-473.

Stone, H. Factors influencing the behavioral response to odor discrimination--a review. J. Food Sci., 1966, 31, 784-790.

Stone, H., \& Bosley, J. J. Olfactory discrimination and Weber's law. Percept. mot. Skills, 1965, 20, 657-665.

Stone, H., Ough, C. S., \& Pangbom, R. M. Determination of odor difference thresholds. J. Food Sci., 1962, 27, 197-202.

Wenzel, B. M., \& Sieck, M. H. Olfaction. Ann. Rev. Physiol., 1966, $28,381-434$.

\section{Notes}

1. The work reported in this paper was supported by the Detection Research Branch of the U.S. Army Edgewood Arsenal, under Contract DA18-035-AMC-738(A) with Stanford Research Institute. The authors would like to thank Mr. Robert Dehn for synthesis and purification of the odorants, the panel for their cooperation in this phase of the research, and Dr. Leon Otis for his helpful review of the manuscript.

2. Similar experiments using $\beta$-ionone as the test stimulus yielded essentially identical conclusions.

(Accepted for publication February 2, 1967.) 